\title{
Severidade de ferrugem polissora em cultivares de milho e seu efeito na produtividade.*
}

\author{
Christina Dudienas ${ }^{1}$; Gisèle M. Fantin²; Aildson P. Duarte ${ }^{3}$; Marcelo Ticelli; ${ }^{3}$ Ivana M. Bárbaro ${ }^{3}$; Rogério S. Freitas ${ }^{3}$; \\ Paulo C. L. Leão ${ }^{4}$, Gerson Cazentini Filho ${ }^{5}$, Denizart Bolonhezi ${ }^{3}$, Angélica P. Pântano ${ }^{1}$
}

\begin{abstract}
${ }^{1}$ Instituto Agronômico de Campinas, CP. 28, CEP: 13012-970, Campinas-SP. ${ }^{2}$ Instituto Biológico; ${ }^{3}$ Programa Milho IAC, APTA Regional; ${ }^{4}$ CATI, EDR de Orlândia, ${ }^{5}$ CATI, CA de Cardoso. *Trabalho apresentado no XXVII Congresso Nacional de Milho e Sorgo

Autor para correspondência: Christina Dudienas (dudienas@iac.sp.gov.br)

Data de chegada: 30/09/2011. Aceito para publicação em: 30/03/2011.
\end{abstract}

\section{RESUMO}

Dudienas, C.; Fantin, G.M.; Duarte, A.P.; Ticelli, M.; Bárbaro, I.M.; Freitas, R.S.; Leão, P.C.L.; Cazentini Filjo, G.; Bolonhezi, D.; Pântano, A.P. Severidade de ferrugem polissora em cultivares de milho e seu efeito na produtividade. Summa Phytopathologica, v.39, n.1, p.16-23, 2013.

\begin{abstract}
A ferrugem polissora, causada por Puccinia polysora Underw. é uma das doenças mais destrutivas da cultura do milho, ocorrendo em importantes áreas de produção desta cultura no Brasil. A principal forma de controle desta doença é o uso de cultivares resistentes, havendo no mercado um grande número de cultivares com diferentes graus de resistência. O objetivo deste trabalho foi avaliar a reação de cultivares comerciais de milho quanto à resistência à ferrugem polissora, em diferentes localidades no Estado de São Paulo, correlacionando com a produtividade. Foram avaliados 50 híbridos simples e triplos (HST) e 22 híbridos duplos e variedades de milho (HDV) em uso pelos agricultores no ano agrícola 2005/2006 quanto à sua reação à ferrugem
\end{abstract}

polissora em seis locais nas regiões oeste e centro-norte do Estado de São Paulo. Nos experimentos com HST, as cultivares mais resistentes e que tiveram as maiores produtividades foram: 30F80, 30F90, 30K 73, AG 7000, DAS 2B710, DKB 191, DKB 466 e Impacto. Dentre os $\mathrm{HDV}$, destacaram-se como as mais resistentes e apresentando as maiores produtividades: $30 \mathrm{~S} 40$ e AG 2040. A redução de produtividade em função da severidade da ferrugem polissora, avaliada no estádio de grãos pastosos, variou de 3,5\% para cultivares com aproximadamente $2,5 \%$ de área foliar afetada a $20,3 \%$ para cultivares com, em média, $39 \%$ de área foliar afetada, em relação às cultivares com maior resistência à doença $(1,4 \%$ de área foliar afetada).

Palavras-chave adicionais: Puccinia polysora, doença foliar, correlação, Zea mays

\section{ABSTRACT}

Dudienas, C.; Fantin, G.M.; Duarte, A.P.; Ticelli, M.; Bárbaro, I.M.; Freitas, R.S.; Leão, P.C.L.; Cazentini Filjo, G.; Bolonhezi, D.; Pântano, A.P. Severity of southern rust in maize cultivars and its effect on yield. Summa Phytopathologica, v.39, n.1, p.16-23, 2013.

Southern rust, caused by Puccinia polysora Underw., has become one of the most destructive diseases affecting maize, occurring in important areas of production of this crop in Brazil. Using resistant cultivars is the most efficient means to control this disease, and there are a large number of cultivars with different resistance degrees in the market. The aim of this study was to evaluate the reaction of commercial maize cultivars for resistance to southern rust in different localities of São Paulo State, correlated to yield. A total of 50 simple and triple hybrids (HST) and 22 double hybrids and varieties of maize (HDV) in use by farmers were evaluated in 2005/2006 for their reaction to southern rust in six locations in western and north-central regions of São Paulo State. In the experiments with HST, the most resistant cultivars with the highest yields were: 30F80, 30F90, 30K73, AG 7000, DAS 2B710, DKB 191, DKB 466 and Impacto. Among $\mathrm{HDV}$, the most resistant ones presenting the highest yields were: $30 \mathrm{~S} 40$ and AG 2040. Yield losses due to the severity of southern rust, assessed in the stage of pastry grain, ranged from $3.5 \%$, for cultivars with approximately $2.5 \%$ of leaf area affected by the disease, to $20.3 \%$ for cultivars with $39 \%$ of the leaf area affected, compared to cultivars of higher resistance to the disease (1.4\% affected leaf area).

Additional keywords: Puccinia polysora, leaf disease, correlation, Zea mays.

A ferrugem polissora, causada por Puccinia polysora Underw. é uma das doenças mais destrutivas da cultura do milho, ocorrendo em importantes áreas de produção no Brasil. Foi observada pela primeira vez na África em 1949, causando epidemia (11). No Estado de São Paulo é mais recente, tendo sido constatada no final da década de 80 , causando seca prematura de cultivares suscetíveis (6).

A doença caracteriza-se pela presença de pústulas circulares a ovais de coloração marrom canela clara a alaranjada medindo 0,2 a 2,0 $\mathrm{mm}$ de comprimento, densamente distribuídas, principalmente, na superfície superior das folhas. Os urediniosporos, formados no interior das pústulas, têm coloração amarela a dourada e são tipicamente elipsóides ou ovóides. Os teliossoros são raros, aparecendo em círculos ao redor das pústulas urediniais, com 0,2 a $0,5 \mathrm{~mm}$ de diâmetro, de cor marrom chocolate a preta. $\mathrm{O}$ fungo geralmente infecta folhas completamente expandidas da planta e a doença torna-se mais severa à medida que a planta se desenvolve.

Essa ferrugem pode ser confundida com a ferrugem comum, causada por Puccinia sorghi, no entanto, os urediniosporos desta última são levemente mais escuros, menores e arredondados, produzidos em uredínias mais alongadas, de cor marrom canela escura e, como $P$. 
sorghi, geralmente, se estabelece no cartucho das folhas, a infecção resulta no desenvolvimento de pústulas em faixas transversais nas folhas. P. polysora é comumente mais destrutiva que $P$. sorghi, podendo causar morte precoce das plantas de milho (15).

Patógenos causadores de ferrugens se reproduzem abundantemente e quando em condições favoráveis infectam e se dispersam rapidamente, mesmo a partir de uma quantidade mínima de inóculo, podendo dar origem a epidemias devastadoras. O inverso é também verdadeiro, ou seja, caso as condições de ambiente sejam desfavoráveis, o inóculo presente, ainda que em elevada quantidade, não é suficiente para garantir progresso epidêmico (7).

A ocorrência de ferrugem polissora é favorecida por altas temperaturas, ao redor de $27^{\circ} \mathrm{C}$, e alta umidade relativa (15). Epidemias de ferrugem polissora no campo parecem ser mais influenciadas por diferenças nos regimes de temperaturas em diferentes locais, uma vez que, embora sempre necessário, o período de molhamento para se estabelecer a infecção com sucesso é mínimo ( 2 a 4 horas). Embora longos períodos de molhamento sejam favoráveis à infecção, a mesma condição pode inibir outras fases do ciclo de relações patógenoshospedeiro, como a esporulação e a disseminação, por exemplo (7). A duração do período de molhamento pode ser vista como um fator para que se estabeleça a infecção (7), enquanto a temperatura parece determinar a rapidez e a extensão da epidemia $(7,8)$. A faixa ótima para a infecção da planta é de 25 a $28^{\circ} \mathrm{C}$, com muito rápida diminuição acima de $29{ }^{\circ} \mathrm{C}$ e abaixo de $23{ }^{\circ} \mathrm{C}(2,8,13)$. Estudos realizados por Melching (9) sobre a taxa de desenvolvimento da doença demonstraram que o fungo demora mais tempo para produzir pústulas em temperaturas mais baixas. Este mesmo autor observou também que uma diminuição da temperatura no período posterior ao da inoculação pode aumentar mais o tempo para início da esporulação do que se as plantas fossem mantidas desde o início nessa faixa inferior de temperatura.

A dispersão do fungo a longas distâncias é feita pelo vento e, sendo um patógeno biotrófico, sua sobrevivência no campo depende da presença de plantas vivas (2). É uma doença favorecida por altitudes abaixo de $900 \mathrm{~m}$ (15).

A principal forma de controle da ferrugem polissora é o uso de cultivares resistentes, sendo que sua obtenção é dificultada pela grande variabilidade do patógeno. No Brasil foram observados 17 padrões de virulência de $P$. polysora, entre 60 isolados testados, coletados em diferentes áreas de ocorrência da doença, baseado na reação de seis híbridos experimentais utilizados como diferenciadores. Entre esses, três foram mais frequentes, tendo sido observados em todos locais amostrados, indicando uma possível ausência de diferenciação geográfica entre populações do fungo prevalentes no país (3). A identificação desses diferentes padrões de virulência de $P$. polysora indica a presença de variabilidade na população deste patógeno no Brasil, conforme já constatado por diversos autores em outros países $(14,16,17)$.

A severidade da doença, estudada através de semeaduras quinzenais no período de setembro a abril, durante três anos, em Santa Cruz das Palmeiras - SP, foi crescente até janeiro e decrescente após este mês, com pico nos ensaios semeados na primeira quinzena de janeiro (1, 10). Também Juliatti \& Souza (8), estudando o efeito de doenças foliares em 14 híbridos, plantados em duas épocas de semeadura de milho safrinha em Itumbiara - GO, observaram uma maior severidade de $P$. polysora naquele realizado em fevereiro, em relação ao realizado em março. Esses autores não observaram diferença entre as cultivares quanto à severidade da doença, mas esse nível foi baixo nos dois períodos.
No Estado de São Paulo, a ferrugem polissora ocorre com maior severidade nas regiões oeste e centro-norte, principalmente nos plantios mais tardios da safra de verão. Em condições favoráveis à sua ocorrência, algumas cultivares testadas em ensaios regionais de avaliação de cultivares tiveram mais de $75 \%$ de área foliar afetada pela doença (4). Danos causados por essa doença têm sido observados com bastante frequência e comprovam a importância da doença. Resende et al. (12) constataram uma redução de até $56 \%$ na produtividade do milho, causada por $P$. polysora. Pinho et al. (11) verificaram que o dano causado em termos de produtividade de grãos foi tanto maior quanto mais precocemente ocorreu a doença. Fantin et al. (6) obtiveram um coeficiente de correlação negativo e significativo a $1 \%$ de probabilidade entre severidade da doença e produtividade de 36 cultivares em experimento onde a nota média da doença foi 4,0 (5\% de área foliar afetada) variando de 1,6 a 7,1 entre as cultivares.

O objetivo deste trabalho foi avaliar a reação de cultivares comerciais de milho quanto à resistência à ferrugem polissora em diferentes locais no Estado de São Paulo, correlacionando com a produtividade.

\section{MATERIAL E MÉTODOS}

Foram avaliados 50 híbridos simples e triplos (HST) e 22 híbridos duplos e variedades de milho (HDV) em uso pelos agricultores, no ano agrícola 2005/2006, quanto à sua reação à ferrugem polissora. Os HST foram avaliados em quatro locais nas regiões centro-norte e oeste do Estado de São Paulo: Cardoso (420 m de altitude), Colina (568 m de altitude), Guaíra (490 m de altitude) e Ribeirão Preto (620 m de altitude) e os HDV em três locais nas mesmas regiões: Colina, Guaíra e Adamantina (450 m de altitude). As datas de instalação dos ensaios foram as seguintes: Cardoso: 22/12/2005, Colina: 27/12/2005, Guaíra: 25/11/2005, Ribeirão Preto: 28/11/2005 e Adamantina: 22/12/2005.

$\mathrm{O}$ delineamento experimental utilizado foi o de blocos ao acaso com três repetições para os experimentos com HST e quatro repetições para os experimentos com HDV. Cada parcela consistiu de quatro linhas de $5 \mathrm{~m}$ e espaçamento de $0,90 \mathrm{~m}$. A população de plantas foi ajustada através de desbaste, aproximadamente 15 a 21 dias após a semeadura, para 55.500 e 57.500 plantas por hectare nos ensaios HDV e HST, respectivamente.

A avaliação da severidade das doenças nos ensaios foi realizada em plantas na fase de grãos pastosos, exceto em Cardoso que foi no estádio de grãos farináceos, através de notas de 1 a 9 , respectivamente para $0 ; 1 ; 2,5 ; 5 ; 10 ; 25 ; 50 ; 75$ e mais de $75 \%$ de área foliar afetada pela doença, com auxílio de uma escala diagramática da AGROCERES (1). A avaliação foi realizada nas duas linhas centrais atribuindo-se uma nota média de severidade para cada parcela. .

Foram efetuadas análises de variância da produtividade e severidade da doença. A comparação de médias de produtividade foi realizada pelo teste de Tukey e da severidade pelo teste de Scott-Knott, ambos a $5 \%$ de probabilidade. Para análise, os dados de severidade foram transformados em raiz $(\mathrm{x}+0,5)$.

Para o estudo da influência das doenças sobre a produtividade média do milho, foi obtida a correlação entre produtividade e severidade da doença. As cultivares foram agrupadas em classes com diferentes níveis de severidade, em função dos resultados de agrupamento de médias pelo teste de Scott-Knott, para minimizar suas diferenças de potencial produtivo e demais características inerentes a cada híbrido. Foram obtidos os valores de severidade e de produtividade médias em cada classe. Obteve-se também a equação de ajuste da produtividade 
em função da severidade da doença nas classes obtidas, através de regressão linear, nos intervalos estudados e o coeficiente de determinação $\left(\mathrm{R}^{2}\right)$ entre estas duas variáveis.

Foram coletados dados de temperatura e precipitação pluviométrica em Guaíra e Ribeirão Preto para se observar a influência destes fatores climáticos na severidade da doença. Nos demais locais não havia postos meteorológicos para tais coletas.

\section{RESULTADOS E DISCUSSÃO}

A ferrugem polissora ocorreu com maior severidade nos HST em Cardoso, Colina e Guaíra, seguidos de Ribeirão Preto e as melhores correlações da severidade com produtividade foram obtidas em Colina, Guaíra e Cardoso, na sequência (Tabela 1). Em Cardoso, a elevada severidade encontrada deveu-se, principalmente à avaliação tardia, após a época mais adequada, em estágio mais adiantado da epidemia, não indicando que a doença tenha sido mais severa neste local. A avaliação tardia da doença neste local pode explicar os menores valores dos coeficientes de correlação (Tabela1) e de determinação (Figura 2), do que em Colina e Guaíra, apesar da maior severidade obtida nas avaliações. Em Ribeirão Preto foram constatadas as menores severidades da doença e também as menores produtividades e não foi possível detectar o efeito da doença na produtividade. Essas menores produtividades foram devidas a outros fatores como uma baixa precipitação pluviométrica no período de enchimento de grãos e também ocorrência de mancha de diplódia, causada por Stenocarpella macrospora, em severidade de até $5 \%$ de área foliar afetada.

Nos HDV a maior severidade da doença foi observada em Colina, seguida de Guaíra, com produtividade média das cultivares maior em Guaíra (Tabela 2).

Todos os locais onde ocorreu a ferrugem polissora estão localizados em pontos com altitudes iguais ou inferiores a $620 \mathrm{~m}$, evidenciando o favorecimento dessa doença em locais abaixo de $900 \mathrm{~m}$, citado por Shurtleff (15).

Na Figura 1 estão apresentados os dados climáticos de Ribeirão Preto e Guaíra. Em Guaíra os dados de temperaturas e precipitação pluviométrica indicam condições muito favoráveis para a ocorrência
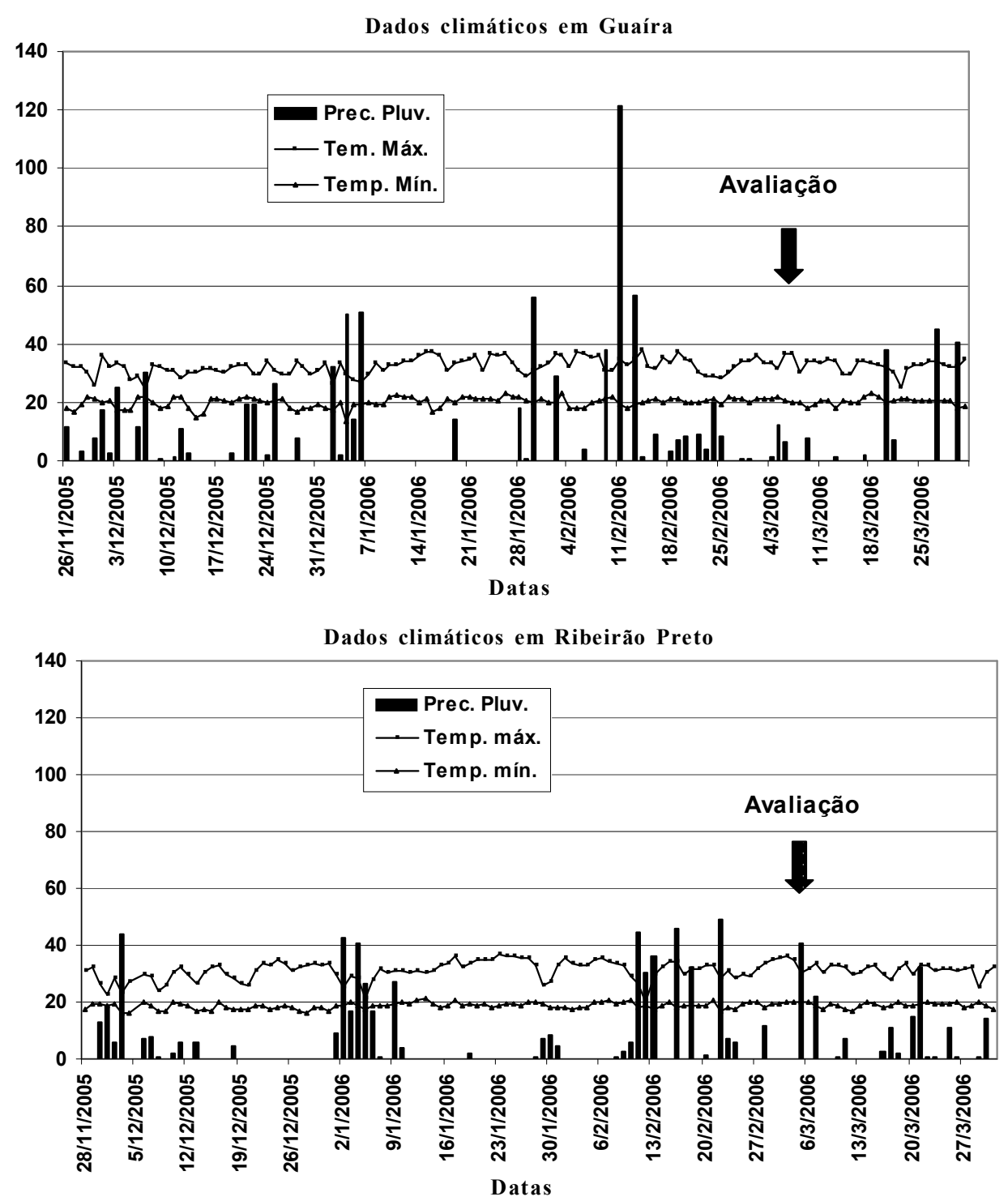

Figura 1. Precipitação pluviométrica e temperaturas máximas e mínimas em Guaíra e Ribeirão Preto no período de experimentação, no Estado de São Paulo, durante a safra 2005/2006. 
Tabela 1. Severidade de ferrugem polissora e produtividade de híbridos simples e triplos de milho (HST) em quatro locais do Estado de São Paulo, no ano agrícola 2005/2006.

\begin{tabular}{|c|c|c|c|c|c|c|c|c|c|c|c|c|}
\hline \multirow{3}{*}{$\begin{array}{l}\text { Cultivar } \\
\text { Impacto }\end{array}$} & \multicolumn{3}{|c|}{ Cardoso } & \multicolumn{3}{|c|}{ Colina } & \multicolumn{3}{|c|}{ Guaíra } & \multicolumn{3}{|c|}{ Ribeirão Preto } \\
\hline & \multicolumn{2}{|c|}{ notas 1} & \multirow{2}{*}{$\begin{array}{l}\mathbf{k g . h a} \mathbf{a}^{-1} \\
8.572\end{array}$} & \multicolumn{2}{|c|}{ notas } & \multirow{2}{*}{$\begin{array}{l}\mathbf{k g} \cdot \mathbf{h a}^{-1} \\
7.788\end{array}$} & \multicolumn{2}{|c|}{ notas } & \multirow{2}{*}{$\begin{array}{l}\mathrm{kg} \mathrm{ha}^{-1} \\
9.293\end{array}$} & \multicolumn{2}{|c|}{ notas } & \multirow{2}{*}{$\frac{\text { kg.ha }^{-1}}{6.894}$} \\
\hline & 2,0 & $\mathrm{f}$ & & 2,0 & $\mathrm{e}$ & & 2,3 & $\mathrm{~d}$ & & 1,0 & $\mathrm{c}$ & \\
\hline AG 7000 & 2,6 & $\mathrm{f}$ & 6.914 & 3,0 & $\mathrm{~d}$ & 7.697 & 3,0 & $\mathrm{~d}$ & 7.569 & 1,7 & $\mathrm{c}$ & 7.578 \\
\hline $30 \mathrm{~K} 73$ & 2,7 & $\mathrm{f}$ & 7.626 & 3,0 & $\mathrm{~d}$ & 8.217 & 2,7 & $\mathrm{~d}$ & 9.208 & 1,7 & $\mathrm{c}$ & 8.282 \\
\hline DAS $2 B 710$ & 2,8 & e & 6.742 & 2,0 & $\mathrm{e}$ & 8.528 & 1,7 & $\mathrm{~d}$ & 8.601 & 1,3 & $\mathrm{c}$ & 8.490 \\
\hline A 2555 & 2,9 & $\mathrm{e}$ & 6.531 & 3,3 & $\mathrm{c}$ & 6.224 & 4,0 & $\mathrm{c}$ & 7.243 & 2,0 & $\mathrm{c}$ & 5.171 \\
\hline $30 \mathrm{~F} 80$ & 3,0 & e & 7.262 & 2,7 & $\mathrm{~d}$ & 6.479 & 3,0 & $\mathrm{~d}$ & 7.785 & 1,0 & $\mathrm{c}$ & 5.253 \\
\hline DKB 789 & 3,0 & $\mathrm{e}$ & 6.694 & 5,0 & $\mathrm{~b}$ & 7.230 & 3,7 & $\mathrm{c}$ & 7.731 & 2,0 & $\mathrm{c}$ & 6.104 \\
\hline $30 \mathrm{~F} 90$ & 3,2 & $\mathrm{e}$ & 6.915 & 2,0 & $\mathrm{e}$ & 9.076 & 2,0 & $\mathrm{~d}$ & 7.994 & 1,0 & $\mathrm{c}$ & 6.263 \\
\hline DKB 466 & 3,5 & $\mathrm{e}$ & 7.631 & 2,7 & $\mathrm{~d}$ & 7.820 & 3,3 & $\mathrm{c}$ & 7.396 & 1,3 & $\mathrm{c}$ & 5.733 \\
\hline BRS 1010 & 3,5 & $\mathrm{e}$ & 7.181 & 5,3 & $\mathrm{~b}$ & 6.515 & 4,0 & $\mathrm{c}$ & 7.555 & 2,0 & $\mathrm{c}$ & 7.033 \\
\hline DKB 191 & 3,5 & e & 6.600 & 2,7 & $\mathrm{~d}$ & 8.503 & 2,0 & $\mathrm{~d}$ & 8.609 & 2,0 & $\mathrm{c}$ & 7.225 \\
\hline $30 \mathrm{~F} 35$ & 3,7 & $\mathrm{~d}$ & 7.183 & 4,7 & $\mathrm{~b}$ & 8.041 & 4,0 & $\mathrm{c}$ & 8.970 & 2,7 & $\mathrm{~b}$ & 7.313 \\
\hline AG 8088 & 3,8 & $\mathrm{~d}$ & 6.894 & 3,7 & $\mathrm{c}$ & 7.906 & 3,3 & $\mathrm{c}$ & 8.529 & 1,7 & $\mathrm{c}$ & 8.746 \\
\hline AG 5020 & 4,0 & $\mathrm{~d}$ & 7.342 & 3,3 & $\mathrm{c}$ & 8.219 & 3,0 & $\mathrm{~d}$ & 8.231 & 1,7 & $\mathrm{c}$ & 7.571 \\
\hline AG 7010 & 4,0 & $\mathrm{~d}$ & 6.267 & 2,7 & $\mathrm{~d}$ & 6.520 & 2,3 & $\mathrm{~d}$ & 7.471 & 1,0 & $\mathrm{c}$ & 6.889 \\
\hline AGN 20A20 & 4,2 & $\mathrm{~d}$ & 6.188 & 3,7 & $\mathrm{c}$ & 7.056 & 3,3 & $\mathrm{c}$ & 7.019 & 1,3 & $\mathrm{c}$ & 7.019 \\
\hline $30 \mathrm{~F} 98$ & 4,3 & $\mathrm{~d}$ & 6.619 & 5,7 & $\mathrm{~b}$ & 7.051 & 3,7 & $\mathrm{c}$ & 7.449 & 1,7 & $\mathrm{c}$ & 6.390 \\
\hline XB 7253 & 4,3 & $\mathrm{~d}$ & 6.477 & 5,0 & $\mathrm{~b}$ & 6.105 & 3,7 & $\mathrm{c}$ & 7.025 & 2,0 & $\mathrm{c}$ & 7.227 \\
\hline DKB 979 & 4,3 & $\mathrm{~d}$ & 6.017 & 5,0 & $\mathrm{~b}$ & 6.221 & 3,7 & $\mathrm{c}$ & 7.842 & 2,0 & $\mathrm{c}$ & 7.185 \\
\hline A 010 & 4,5 & $\mathrm{~d}$ & 6.932 & 5,3 & $\mathrm{~b}$ & 5.760 & 4,0 & $\mathrm{c}$ & 7.092 & 2,0 & $\mathrm{c}$ & 6.726 \\
\hline BRS 3003 & 4,5 & $\mathrm{~d}$ & 6.746 & 6,3 & $\mathrm{a}$ & 6.106 & 5,0 & $\mathrm{~b}$ & 6.853 & 3,3 & $\mathrm{~b}$ & 6.588 \\
\hline DAS 2 C599 & 4,7 & $\mathrm{~d}$ & 6.823 & 4,0 & $\mathrm{c}$ & 5.805 & 2,7 & $\mathrm{~d}$ & 7.301 & 1,3 & $\mathrm{c}$ & 6.804 \\
\hline Balu 761 & 4,7 & $\mathrm{~d}$ & 6.576 & 5,7 & $\mathrm{~b}$ & 7.152 & 3,0 & $\mathrm{~d}$ & 8.316 & 2,3 & $\mathrm{c}$ & 7.023 \\
\hline A 015 & 4,7 & $\mathrm{~d}$ & 5.947 & 5,3 & $\mathrm{~b}$ & 6.280 & 4,7 & $\mathrm{~b}$ & 6.730 & 1,7 & $\mathrm{c}$ & 5.502 \\
\hline AG 8060 & 5,0 & $\mathrm{c}$ & 7.457 & 4,0 & $\mathrm{c}$ & 7.792 & 3,3 & $\mathrm{c}$ & 7.601 & 1,7 & $\mathrm{c}$ & 6.788 \\
\hline NB 7233 & 5,0 & $\mathrm{c}$ & 7.244 & 3,7 & $\mathrm{c}$ & 7.944 & 3,3 & $\mathrm{c}$ & 9.022 & 1,7 & $\mathrm{c}$ & 7.685 \\
\hline BM 2202 & 5,0 & $\mathrm{c}$ & 5.592 & 3,3 & $\mathrm{c}$ & 6.088 & 3,7 & $\mathrm{c}$ & 6.734 & 1,3 & $\mathrm{c}$ & 5.477 \\
\hline AL Bandeirante & 5,0 & $\mathrm{c}$ & 5.490 & 6,3 & $\mathrm{a}$ & 5.159 & 4,0 & $\mathrm{c}$ & 5.372 & 3,0 & $\mathrm{~b}$ & 4.625 \\
\hline Somma & 5,2 & $\mathrm{c}$ & 7.160 & 6,3 & $\mathrm{a}$ & 6.413 & 4,0 & $\mathrm{c}$ & 7.033 & 2,3 & $\mathrm{c}$ & 6.500 \\
\hline GNZ 2005 & 5,2 & $\mathrm{c}$ & 6.810 & 3,3 & $\mathrm{c}$ & 6.057 & 2,7 & $\mathrm{~d}$ & 6.837 & 2,7 & $\mathrm{~b}$ & 6.245 \\
\hline Master & 5,2 & $\mathrm{c}$ & 6.736 & 5,7 & $\mathrm{~b}$ & 6.207 & 5,7 & $\mathrm{a}$ & 7.481 & 2,3 & $\mathrm{c}$ & 6.613 \\
\hline XB 7116 & 5,2 & $\mathrm{c}$ & 6.042 & 5,3 & $\mathrm{~b}$ & 6.413 & 3,3 & $\mathrm{c}$ & 6.384 & 2,7 & $\mathrm{~b}$ & 5.771 \\
\hline BRS 1030 & 5,3 & $\mathrm{c}$ & 6.865 & 5,3 & $\mathrm{~b}$ & 6.975 & 4,0 & $\mathrm{c}$ & 7.580 & 1,7 & $\mathrm{c}$ & 5.856 \\
\hline GNZ 2004 & 5,3 & $\mathrm{c}$ & 6.675 & 3,0 & $\mathrm{~d}$ & 6.639 & 3,3 & $\mathrm{c}$ & 6.938 & 1,0 & $\mathrm{c}$ & 5.573 \\
\hline DKB 350 & 5,4 & $\mathrm{c}$ & 6.964 & 5,7 & $\mathrm{~b}$ & 6.328 & 4,0 & $\mathrm{c}$ & 8.395 & 1,3 & $\mathrm{c}$ & 7.025 \\
\hline DG 501 & 5,5 & $\mathrm{c}$ & 6.859 & 3,7 & $\mathrm{c}$ & 6.226 & 2,7 & $\mathrm{~d}$ & 6.552 & 1,0 & $\mathrm{c}$ & 6.146 \\
\hline DKB 390 & 5,7 & $\mathrm{c}$ & 7.573 & 4,0 & $\mathrm{c}$ & 8.083 & 4,0 & $\mathrm{c}$ & 7.090 & 2,0 & $\mathrm{c}$ & 8.823 \\
\hline Maximus & 5,7 & $\mathrm{c}$ & 6.905 & 4,3 & $\mathrm{c}$ & 6.584 & 4,0 & $\mathrm{c}$ & 6.534 & 1,3 & $\mathrm{c}$ & 7.351 \\
\hline DKB 330 & 5,7 & $\mathrm{c}$ & 6.108 & 6,3 & $\mathrm{a}$ & 5.131 & 4,7 & $\mathrm{~b}$ & 7.554 & 2,0 & $\mathrm{c}$ & 6.352 \\
\hline AS 1575 & 5,8 & $\mathrm{c}$ & 6.357 & 6,0 & $\mathrm{a}$ & 6.189 & 6,0 & $\mathrm{a}$ & 7.269 & 3,0 & $\mathrm{~b}$ & 7.477 \\
\hline Garra & 6,0 & $\mathrm{c}$ & 6.660 & 6,3 & $\mathrm{a}$ & 5.739 & 5,7 & $\mathrm{a}$ & 6.153 & 2,3 & $\mathrm{c}$ & 5.695 \\
\hline Balu 551 & 6,0 & $\mathrm{c}$ & 6.489 & 6,3 & $\mathrm{a}$ & 6.029 & 4,7 & $\mathrm{~b}$ & 6.550 & 2,7 & $\mathrm{~b}$ & 5.252 \\
\hline AGN 31A31 & 6,2 & $\mathrm{c}$ & 7.126 & 4,7 & $\mathrm{~b}$ & 6.414 & 3,0 & $\mathrm{~d}$ & 7.393 & 1,7 & $\mathrm{c}$ & 7.163 \\
\hline DKB 455 & 6,3 & $\mathrm{c}$ & 6.409 & 4,7 & $\mathrm{~b}$ & 6.365 & 4,3 & $\mathrm{~b}$ & 7.504 & 2,7 & $\mathrm{~b}$ & 7.308 \\
\hline AS 1567 & 6,8 & $\mathrm{~b}$ & 7.425 & 6,0 & $\mathrm{a}$ & 5.945 & 4,3 & $\mathrm{~b}$ & 7.174 & 2,0 & $\mathrm{c}$ & 6.815 \\
\hline DAS 8480 & 7,0 & $\mathrm{~b}$ & 6.323 & 4,0 & $\mathrm{c}$ & 6.699 & 6,0 & $\mathrm{a}$ & 7.972 & 4,0 & a & 7.539 \\
\hline XB 7110 & 7,2 & $\mathrm{~b}$ & 6.105 & 7,0 & $\mathrm{a}$ & 5.544 & 5,3 & $\mathrm{~b}$ & 6.948 & 4,3 & a & 6.315 \\
\hline AS 1570 & 8,5 & $\mathrm{a}$ & 7.084 & 6,7 & $\mathrm{a}$ & 4.550 & 7,0 & $\mathrm{a}$ & 6.369 & 4,7 & $\mathrm{a}$ & 6.121 \\
\hline $30 P 70$ & 8,8 & a & 6.252 & 7,0 & $\mathrm{a}$ & 4.835 & 6,3 & $\mathrm{a}$ & 7.191 & 3,3 & $\mathrm{~b}$ & 6.571 \\
\hline AS 1548 & 8,8 & $\mathrm{a}$ & 4.437 & 7,0 & $\mathrm{a}$ & 4.435 & 6,7 & $\mathrm{a}$ & 5.858 & 2,7 & $\mathrm{~b}$ & 5.242 \\
\hline Média & 4,9 & & 6.717 & 4,6 & & 6.662 & 3,9 & & 7.426 & 2,1 & & 6.667 \\
\hline C.V. $(\%)$ & 5,6 & & 8,9 & 6,9 & & 9,4 & 9,9 & & 8,9 & 13,6 & & 9,9 \\
\hline Dms (Tukey 5\%) & & & 2.007 & & & 2.118 & & & 2.235 & & & 2.222 \\
\hline Coef. correlação $(r)^{2}$ & & & & & & & & & & & & \\
\hline
\end{tabular}

${ }^{1}$ Notas de 1 a 9 correspondendo às porcentagens de $0 ; 1 ; 2,5 ; 5 ; 10 ; 25 ; 50 ; 75$ e mais de $75 \%$ de área foliar afetada. Médias seguidas pela mesma letra nas colunas não diferem entre si a $5 \%$ de significância, pelo teste de Scott Knott (para análise, dados transformados em $V_{\mathrm{x}}+0,5$ ). ${ }^{2} \mathrm{r}=$ coeficiente de correlação linear entre produtividade e severidade, considerando a média de três repetições para cada cultivar. ** Significativo a $1 \%$ de probabilidade, pelo teste $\mathrm{t}$. 
Tabela 2. Severidade de ferrugem polissora e produtividade de híbridos duplos e variedades de milho (HDV) em três locais do Estado de São Paulo, no ano agrícola 2005/2006.

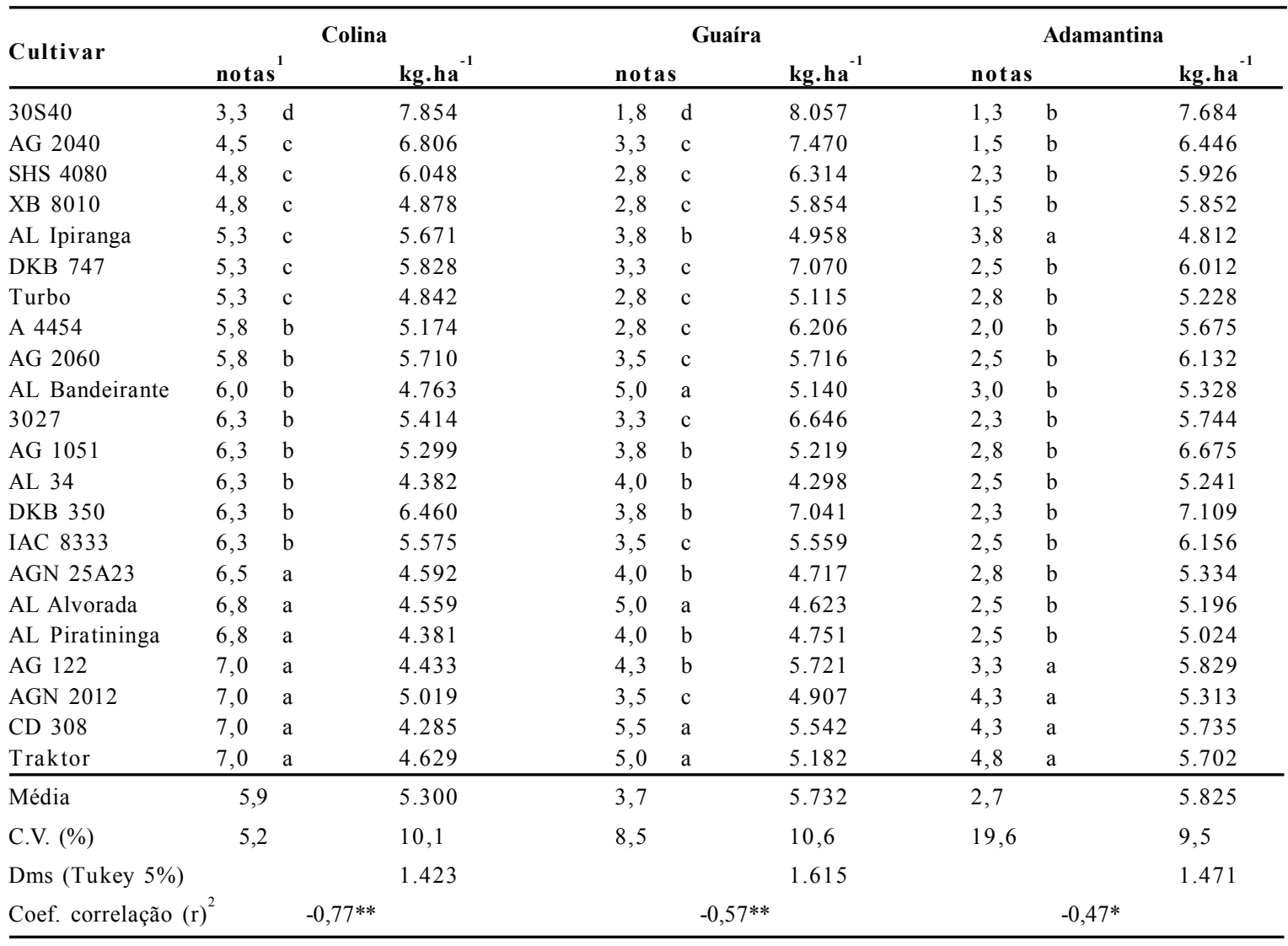

${ }^{1}$ Notas de 1 a 9 correspondendo às porcentagens de $0 ; 1 ; 2,5 ; 5 ; 10 ; 25 ; 50 ; 75$ e mais de $75 \%$ de área foliar afetada pela ferugem polissora. Médias seguidas pela mesma letra nas colunas não diferem entre si a $5 \%$ de significância, pelo teste de Scott Knott (para análise, dados transformados em $\sqrt{x}_{\mathrm{x}}+0,5$ ). ${ }^{2} \mathrm{r}=$ coeficiente de correlação linear entre peso de grãos e notas de severidade, considerando a média de quatro repetições para cada cultivar. ${ }^{* *}$, * Significativo a $1 \%$ e $5 \%$ de probabilidade, respectivamente, pelo teste t.

de ferrugem polissora. No período de um mês anterior à avaliação, por exemplo, a temperatura média diária no local do experimento variou entre $23,8^{\circ} \mathrm{C}$ e $29,2^{\circ} \mathrm{C}$, com precipitação pluviométrica de $293,5 \mathrm{~mm}$. Os valores de temperaturas permaneceram numa faixa bem próxima à ideal para ocorrência da doença, que é favorecida por altas temperaturas, ao redor de $27^{\circ} \mathrm{C}$, sendo a faixa ótima para a infecção da planta de 25 a $28^{\circ} \mathrm{C}$, com muito rápida diminuição acima de $29^{\circ} \mathrm{C}$ e abaixo de $23^{\circ} \mathrm{C}$ $(2,8,13)$. Estes resultados também estão de acordo com as constatações de Melching (9) de que a taxa de desenvolvimento da doença parece ser dependente primariamente da temperatura.

Em Ribeirão Preto, considerando um mesmo período de tempo de um mês anterior à avaliação, a temperatura média diária no local do experimento variou entre $19,2^{\circ} \mathrm{C}$ e $28^{\circ} \mathrm{C}$, com precipitação pluviométrica de 314,5 . Houve nesse período uma queda brusca de temperatura máxima, da faixa de $32^{\circ} \mathrm{C}$ para $19,9^{\circ} \mathrm{C}$, ocorrida em 12/02/ 2006. A temperatura mais baixa pode explicar a menor severidade da doença no experimento pois, conforme Melching (9), o fungo demora mais tempo para produzir pústulas em temperaturas mais baixas. Também segundo esse autor, uma diminuição da temperatura no período posterior ao da inoculação pode aumentar mais o tempo para início da esporulação do que se as plantas fossem mantidas desde o início nesta faixa inferior de temperatura, o que reforça a possibilidade da queda de temperatura ter tido grande influência na redução do desenvolvimento da epidemia da doença nesse local.

Em Ribeirão Preto apenas as cultivares mais suscetíveis apresentaram níveis de 5 a $10 \%$ de área foliar afetada (notas 4 e 5).

Nos locais de maior severidade da doença como em Cardoso e Colina, verificou-se que, para os HST, aproximadamente metade das cultivares avaliadas tiveram notas médias iguais ou acima de 5,0 (10\% de área foliar afetada) e $20 \%$ da cultivares notas iguais ou superiores a 6,0 (25\% de área foliar afetada). Em Guaíra, local onde a doença ocorreu em alta severidade, mas menor que em Cardoso e Colina, 20\% das cultivares tiveram notas iguais ou superiores a 5,0 (Tabela 1).

Nos experimentos de HST as cultivares que se comportaram como mais resistentes e também tiveram produtividades estatisticamente iguais às mais produtivas nas três localidades de alta severidade de doença foram as seguintes: 30F80, 30F90, 30K73, AG 7000, DAS 2B710, DKB 191, DKB 466 e Impacto (Tabela 1).

Nos experimentos de HDV, em Colina, local de maior severidade de ferrugem polissora, $77 \%$ das cultivares tiveram notas iguais ou maiores que 5,0 e 55\% iguais ou maiores que 6,0 e em Guaíra, esses valores foram $18 \%$ e $0 \%$, respectivamente. As cultivares com as menores notas de severidade e maiores produtividades foram $30 \mathrm{~S} 40 \mathrm{e}$ AG 2040 (Tabela 2).

Observa-se que, tanto entre os HST como nos HDV, cultivares moderadamente resistentes apresentaram elevada severidade da ferrugem em condições ambientais muito favoráveis ao desenvolvimento da doença, indicando que nesses locais deve-se ter uma preocupação maior quanto ao plantio de cultivares mais resistentes, para se evitar grandes danos à produtividade. 

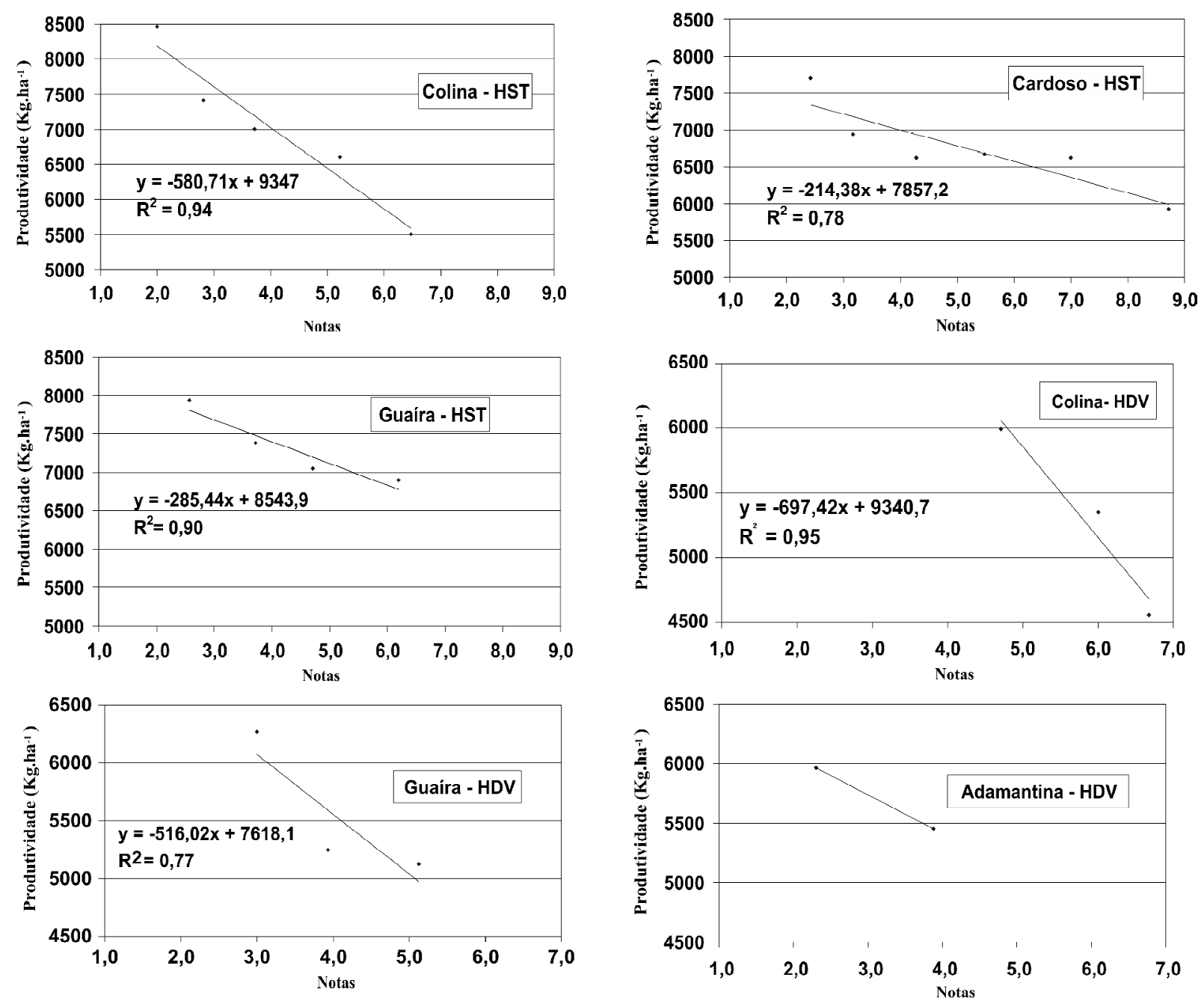

Figura 2. Produtividade de híbridos simples e triplos (HST) e híbridos duplos e variedades (HDV) de milho em função da severidade da ferrugem polissora (notas) no Estado de São Paulo, na safra 2005/2006.

Os resultados obtidos nos experimentos de HST mostram que houve correlação negativa, significativa a $1 \%$ de probabilidade, entre produtividade e severidade da ferrugem polissora em Colina, Guaíra e Cardoso, e não houve correlação entre esses dois fatores em Ribeirão Preto (Tabela 1). Nos experimentos de HDV também se verificou correlação a $1 \%$ de significância em Colina e Guaíra e a $5 \%$ em Adamantina. Esses dados indicam que em locais de maior pressão de ferrugem polissora há correlação negativa entre produtividade e severidade da doença, confirmando resultados de vários autores $(8,11,12)$. Em Adamantina ocorreu alta incidência de enfezamento, o que deve ter interferido na produtividade das cultivares, resultando num menor valor do coeficiente de correlação com a severidade da ferrugem e também numa menor significância desta correlação.

Nos experimentos de HST, em Cardoso as notas médias de severidade de doença variaram de 2,0 a 8,8 , com média geral de 4,9. Em Colina essa variação foi de 2,0 a 7,0, com média geral de 4,6; em Guaíra foi de 2,0 a 7,0, com média geral de 3,9 e em Ribeirão preto de 1,0 a 4,7, com média geral de 2,1 (Tabela 1).

Nos experimentos de HDV em Colina as notas médias de severidade variaram de 3,3 a 7,0, com média geral de 5,9; em Guaíra variaram de 1,8 a 5,5, com média geral de 3,7 e em Adamantina de 1,3 a 4,8, com média geral de 2,7(Tabela 2 ).

Na Figura 2 são apresentados os gráficos da produtividade em função da severidade dos híbridos, agrupados dentro de classes com auxílio do teste de Scott-Knott.

$\mathrm{O}$ ajuste de equações lineares (linhas de tendência) aos dados de produtividade permitiu estimar as porcentagens de danos para cada classe de notas de severidade de ferrugem polissora. Foram obtidos valores de $2 \%$ a $32 \%$ de danos, conforme o grau de severidade da doença para HST e de 3\% a 23\% para HDV (Tabela 3). Em Adamantina, como houve apenas duas classes de resistência, não foi obtida a equação ajustada à reta.

Na média, a redução de produtividade em função da ferrugem polissora foi de $276 \mathrm{~kg} / \mathrm{ha}$ (3,5\%) para cultivares com nota $3,606 \mathrm{~kg} /$ ha $(8,1 \%)$ para nota $4,1005 \mathrm{~kg} / \mathrm{ha}(13,7 \%)$ para nota $5,1242 \mathrm{~kg} / \mathrm{ha}$ $(16,6 \%)$ para nota 6 e $1496 \mathrm{~kg} / \mathrm{ha}(20,3 \%)$ para nota 6,59 (para esse cálculo foram consideradas as notas médias acima de 6 , desconsiderando as notas de 8 e 8,72 de Cardoso), em relação à classe média de maior resistência à doença, com nota 2,33 (Tabela 4). Os valores de Adamantina não foram considerados para o cálculo da redução média da produtividade, pois houve apenas duas classes de resistência nesse local.

Os resultados obtidos neste trabalho comprovam a grande importância da ferrugem polissora na redução da produtividade do milho e a eficiência do uso de cultivares resistentes para o controle da doença, principalmente em locais com condições ambientais mais propícias para o desenvolvimento da doença. 
Tabela 3. Efeito da severidade de ferrugem polissora na produtividade de híbridos simples e triplos (HST) e híbridos duplos e variedades (HDV) de milho no Estado de São Paulo, na safra 2005/2006.

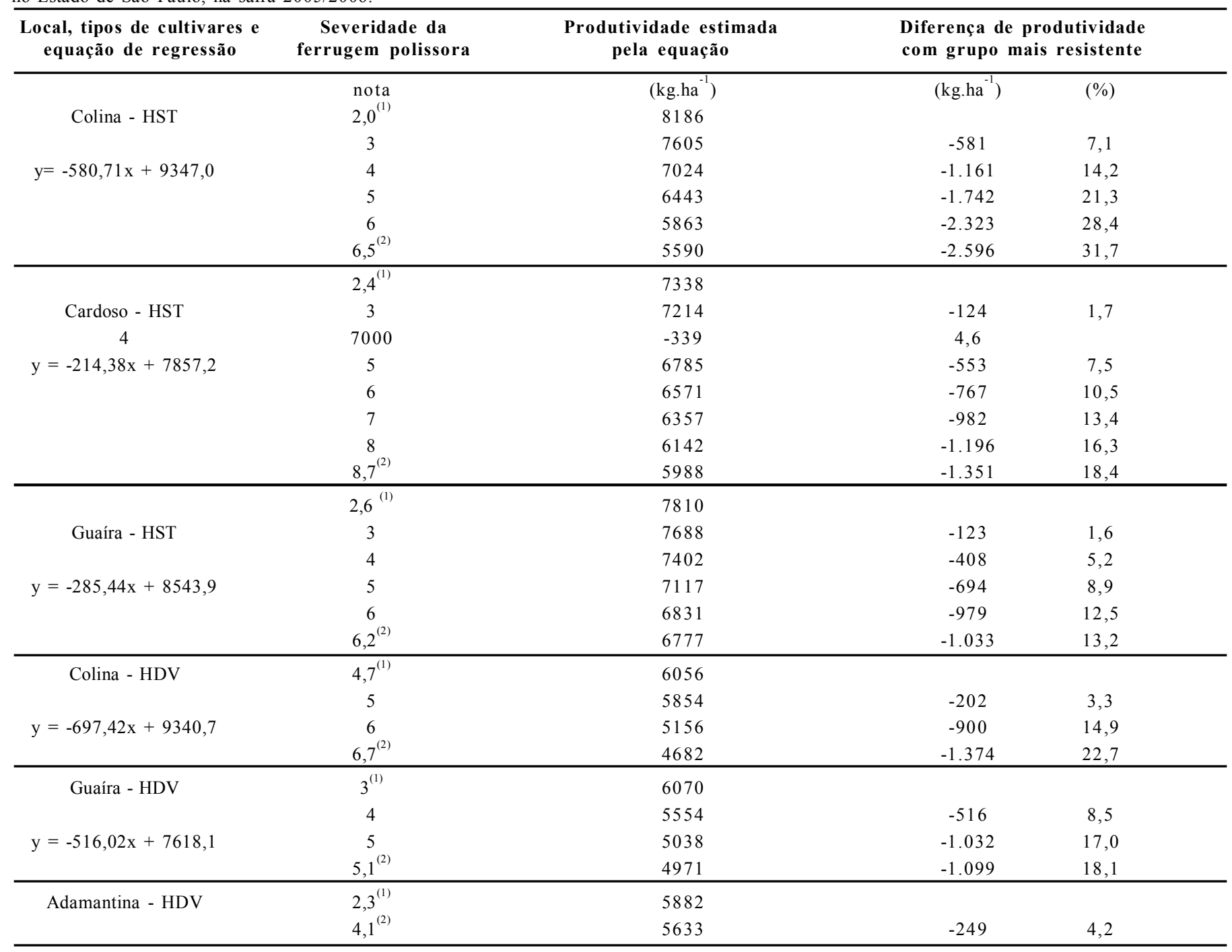

${ }^{(1)}$ Nota média do grupo mais resistente; ${ }^{(2)}$ Nota média do grupo mais suscetível;

Tabela 4. Redução na produtividade de cultivares de milho no Estado de São Paulo, em função da severidade de ferrugem polissora, na safra $2005 / 2006$.

\begin{tabular}{|c|c|c|c|c|}
\hline \multirow[t]{2}{*}{$\begin{array}{l}\text { Classes de } \\
\text { resistência }\end{array}$} & \multicolumn{2}{|c|}{$\begin{array}{c}\text { Severidade da ferrugem } \\
\text { polissora }\end{array}$} & \multicolumn{2}{|c|}{$\begin{array}{l}\text { Redução média da produtividade em } \\
\text { relação ao grupo mais resistente }\end{array}$} \\
\hline & notas & $\% *$ & $\mathrm{~kg} / \mathrm{ha}$ & $\% * *$ \\
\hline \multirow[t]{5}{*}{ Grupo mais resistente } & 2,3 & 1,4 & & \\
\hline & 3,0 & 2,5 & 276 & 3,5 \\
\hline & 4,0 & 5,0 & 606 & 8,1 \\
\hline & 5,0 & 10,0 & 1005 & 13,7 \\
\hline & 6,0 & 25,0 & 1242 & 16,6 \\
\hline Grupo mais suscetível & 6,6 & 39,0 & 1496 & 20,3 \\
\hline
\end{tabular}

*Porcentagem de área foliar afetada pela doença.**Porcentagem de dano à produtividade

\section{REFERÊNCIAS BIBLIOGRÁFICAS}

1. Agroceres. Guia Agroceres de Sanidade. São Paulo, 1994. $64 \mathrm{p}$.

2. Balmer, E.; Pereira, O.A.P. Doenças do milho. In: Paterniani, E.; Viegas, G.P. (Eds.) Melhoramento e produção do milho. 2.ed.
Campinas: Fundação Cargill, 1987. v.2, cap. 14, p.595-634.

3. Casela, C.R.; Ferreira, A.S. Variability in isolates of Puccinia polysora in Brazil. Fitopatologia Brasileira, Brasília, v.27. n.4, p.414-416, jul-ago 2002 .

4. Dudienas, C.; Duarte, A.P.; Castro, J.L.; Paterniani, M.E.A.G.Z.; Bortoleto, N.; Cazentini Filho, G. Avaliação de doenças em cultivares de milho. In: Duarte, A.P.; Paterniani, M.E.A.G.Z. (Coor- 
ds.) Cultivares de milho no Estado de São Paulo: resultado das avaliações regionais IAC/CATI/Empresas 1996/97. Campinas: Instituto Agronômico, 1997. p.53-65. (Documentos IAC, $58)$.

5. Fantin, G.M.; Sawazaki, E.; Merege, W.H.; Denucci, S.; Eichel, O.A.C.; Gallo, P.B.; Martins, A.L.; Castro, J.L.; Sordi, G. Teste regional de cultivares de milho: Avaliação de doenças. Fitopatologia Brasileira, Brasília, v.17. n.2, p.173-174, 1992.

6. Fantin, G.M.; Dudienas, C.; Duarte, A.P.; Paterniani, M.E.A.G.Z.; Reco, P.C.; Coicev, L.; Araujo, A.P.; Bolonhezi, D.; Ocorrência e intensidade de doenças de milho no Estado de São Paulo - Safra 98/ 99. Summa Phytopathologica, Botucatu, v.26, n.1, p.110, 2000.

7. Godoy, C.V. O clima que traz a ferrugem. Cultivar: Grandes Culturas, Pelotas, v.20, p.52-54, 2000.

8. Juliatti, F.C.; Souza, R.M. Efeito de épocas de plantio na severidade de doenças foliares e produtividade de híbridos de milho. Bioscience, Uberlândia, v.21, n.1, p.103-112, 2005.

9. Melching, J.S. Corn rusts: types, races and destructive potencial. In: Annual Corn \& Sorghum Research Conference, 30., Washington. Proceedings. 1975. p.90-115.

10. Pereira, O.A.P. Doenças do milho. In: Kimati, H.; Amorim, L.; Bergamin Filho, A.; Camargo, L.E.A.; Rezende, J.A.M. Manual de Fitopatologia. 3. ed. São Paulo: Agronômica Ceres, 1997. p. $538-555$.

11. Pinho, R.G.V.; Ramalho, M.A.P.; Silva, H.P.; Resende, I.C.; Pozar, G. Danos causados pelas ferrugens polissora e tropical do milho. Fitopatologia Brasileira, Brasília, v.24, n.3, p.400-409, 1999.

12. Resende, I.C.; Silva, H.P.; Pereira, O.A.P.; Perda da produção de milho causada por Puccinia polysora. In: Congresso Nacional de Milho e Sorgo, 20., 1994, Goiânia. Resumos. Sete Lagoas: EMBRAPA-CNPMS, 1994.

13. Rhind, D.; Waterson, J.M.; Deghton, F.C. Ocurrence of Puccinia polysora Underw. In West Africa. Nature, London, v.169, p.631, 1952.

14. Robert, A.L. Host ranges and races of the corn rusts. Phytopathology, Saint Paul, v.52, n.10, p.1010-1012, 1962.

15. Shurtleff, M.C. (Ed.) Compendium of corn diseases. 2.ed. St. Paul: American Phytopathological Press, 1992. $105 \mathrm{p}$.

16. Ullstrup, A.J. Inheritance and linkage of a gene determining resistance in maize to an American race of Puccinia polysora. Phytopathology, Saint Paul, v.55, p.425-428, 1965

17. Yeh, C.C. Studies on rusts of maize. Journal of Agricultural Research of China, Wufeng, v.35, n.1, p.81-93. 1986. 